\title{
EDITORIAL \\ Mastering the art of complex neurosurgical procedures: The Neurosurgical Atlas and the Journal of Neurosurgery
}

\author{
James T. Rutka, MD, PhD \\ Editor-in-Chief, Journal of Neurosurgery Publishing Group, Charlottesville, Virginia
}

$\mathrm{I}$ s 1990, I had the distinct honor of being a neurosurgery fellow in the Department of Neurosurgery at Nagoya University, Japan, under the tutelage of Dr. Kenichiro Sugita. I was the first North American to serve in Nagoya as a "Sugita Scholar" and to learn the myriad techniques mastered and espoused by Professor Sugita in microvascular neurosurgery. At that time, I was impressed with the attention that Dr. Sugita in particular, and the Japanese neurosurgery community in general, paid to capturing operative video recordings of every major case and showing the highlights of the cases at morning conference the next day. I was impressed because these recordings illustrated the technical nuances of microvascular surgery and demonstrated how intraoperative maneuvers could be performed well, or how they could be improved upon. At that time, the editing of video footage was a somewhat arduous process and required the painstaking efforts of dedicated housestaff, whose job it was to complete the task in a relatively short time frame. In this way, the Japanese academic neurosurgery system appeared to be better set up for the effort of producing edited operative videos than the North American system. For myself, by the time I had graduated from neurosurgery residency at the University of Toronto in 1989, I may have videotaped and edited a mere half dozen of my best cases over a period of 7 years. Of course, digital video editing systems have now improved considerably and are quite intuitive to use, making this whole process much easier.

I knew then, but can certainly appreciate even more so now, the importance of improving our abilities as technical neurosurgeons through careful review of the essential elements of a highly edited and annotated operative video. That is why I was absolutely delighted when the opportunity arose for the Journal of Neurosurgery Publishing Group (JNSPG) to join forces with The Neurosurgical Atlas, the brainchild of Aaron Cohen-Gadol, Professor of Neurosurgery at Goodman Campbell Brain and Spine.

The Neurosurgical Atlas, and more specifically its Vol- umes section, was conceived over a decade ago as a collection of text, intraoperative images, illustrations, and videos to document the most difficult moments in neurosurgical procedures. Encouraged by his residents who wanted to review his videos the night before a challenging case, Dr. Cohen-Gadol formed The Neurosurgical Atlas as a not-for-profit entity to advance neurosurgical education and teaching. The Neurosurgical Atlas reflects Dr. Cohen-Gadol's passion for demonstrating how neurosurgical techniques represent a dynamic art (http://www. neurosurgicalatlas.com). Moreover, this Atlas collection is a genuine and sincere inspection of technical pearls for efficient and safe microsurgery, comforting the surgeon the night before the operation.

The establishment of The Neurosurgical Atlas was not without its challenges. Initially, web technology lagged behind in its ability to stream high-quality, high-definition microneurosurgical video footage on the Internet in an organized multimedia and mobile-friendly interface. Efficient editing of long surgical cases required reviewing over 14,000 hours of recorded videos of 2500 operations by the surgeon to create concise videos that truly describe the thought process of the operator and his techniques during the critical parts of the case. In its current format, 9000 illustrations/intraoperative photos and 5000 webpages accompany 1200 videos in over 250 chapters to form the foundation of the Volumes section of The Neurosurgical Atlas. New content is added weekly. Within 6 months of its introduction and by December of 2016, The Neurosurgical Atlas has served a total of over 4200 national and international neurosurgeon/resident members and has an average of 600 viewers per day.

The Neurosurgical Atlas contains the following sections: Volumes, AANS Grand Rounds, and Operative Video Cases. The Cases section is the comprehensive pool of case-based videos; videos of similar procedures are grouped together in the Related Videos section of the chapters in the Volumes section. Each chapter within the 


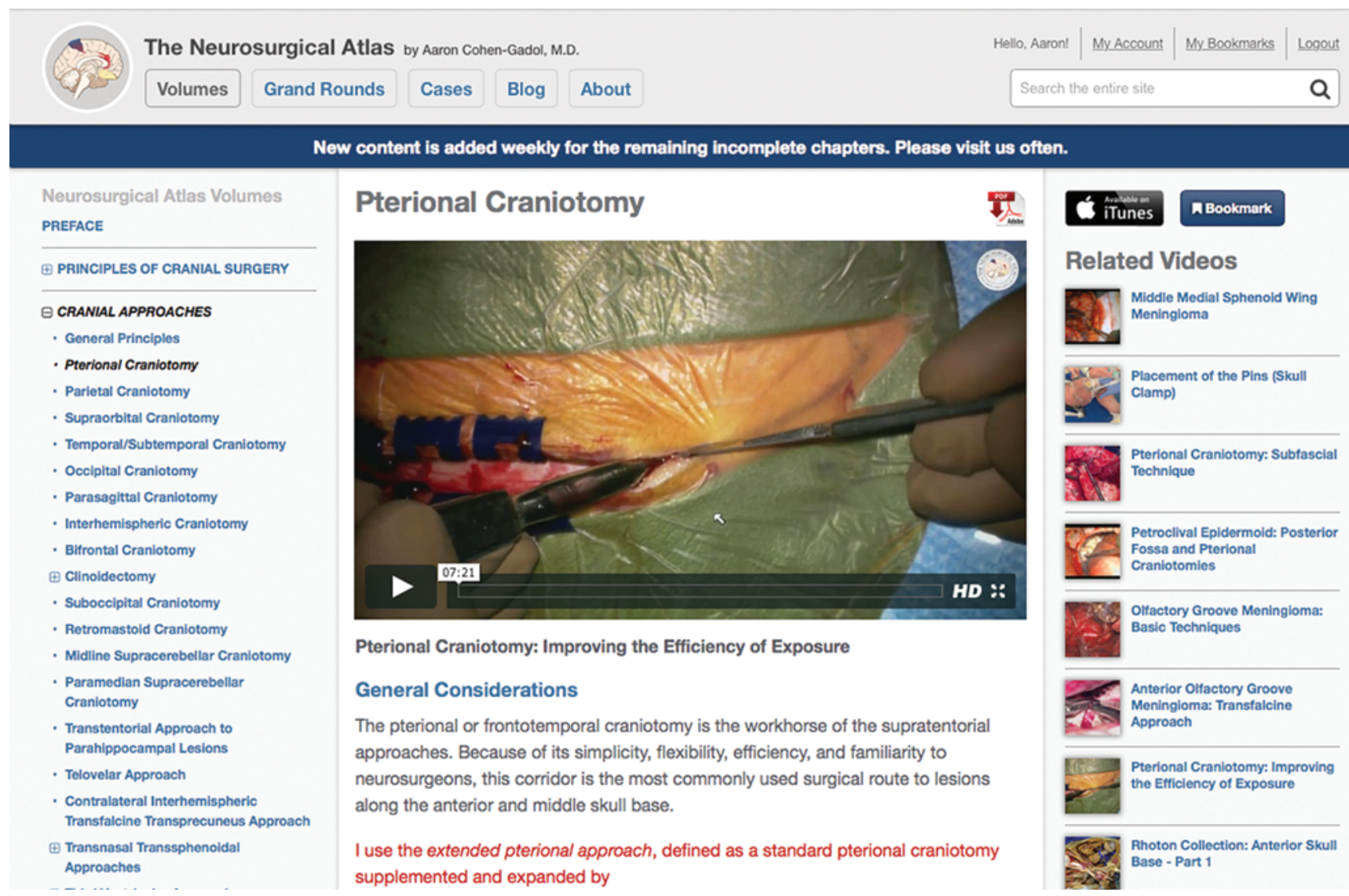

FIG. 1. Screenshot. An example of the page layout for each chapter of The Neurosurgical Atlas (http://www.neurosurgicalatlas. $\mathrm{com})$. The contents of the right-hand column provide the collection of relevant videos for each chapter. Reproduced with permission from Aaron A. Cohen-Gadol: The Neurosurgical Atlas. Figure is available in color online only.

Volumes section contains the navigation on the left, text and illustrations/images in the middle, and Related $\mathrm{Ma}$ terials in the right column below Related Videos (Fig. 1). The Related Materials area contains relevant videos and articles (including Journal of Neurosurgery papers). This consistent page layout allows the reader to interact with the multimedia content of each chapter effectively. All materials are also housed in iTunes U.

Thankfully, since the advent of new technologies for seamless digital transfer, and because of the tireless efforts of the staff of The Neurosurgical Atlas, a web-based product has been created that is, in my opinion, second to none in the world. Just as there are linkages now between the Journal of Neurosurgery and the incredible resource of the "Rhoton Project,"3 so too am I pleased to report newly established linkages between The Neurosurgical Atlas and the Journal of Neurosurgery. With each month's issue of the Journal of Neurosurgery, as many as 5 articles feature a link to The Neurosurgical Atlas. Interested readers can simply click on The Neurosurgical Atlas icon in the top right-hand corner of an article's PDF; the icon links to the landing page of a video on The Neurosurgical Atlas, where the neurosurgical condition from the article is further highlighted with intraoperative nuances from an Operative Video sequence (Fig. 2).

But what is the evidence that the use of video mate- rials is associated with enhanced operative efficiencies, performance-level improvements, and improved patient outcomes? In a study performed by McBeth et al., ${ }^{1}$ quantitative measures of performance were undertaken with video-capture analysis to show that experienced neurosurgeons performing microvascular anastomoses do so using specific tasks that are demonstrated consistently from case to case. In this study, optoelectronic and video motion analyses were shown to be very useful as methods to record kinematic data. ${ }^{1}$ In another study, Sarkiss et al. ${ }^{4}$ showed that the evaluation of intraoperative videos of residents performing craniotomies was helpful in measuring technical proficiency. Such information may be invaluable in comparing skill levels of residents, coaching residents for improvement, and tracking residents longitudinally for progress. ${ }^{4}$ Interestingly, Rapp et al. ${ }^{2}$ recently reported that YouTube (youtube.com) is the most frequently used educational video source for surgical preparation. In this survey study of medical students undertaking general surgery rotations, and general surgery residents and faculty, learners were shown to use YouTube and the Surgical Council on Resident Education (SCORE) portal more than faculty, whereas faculty preferentially used society webpages and commercial videos for surgical preparation. ${ }^{2}$

Now that we have established formal linkages between 

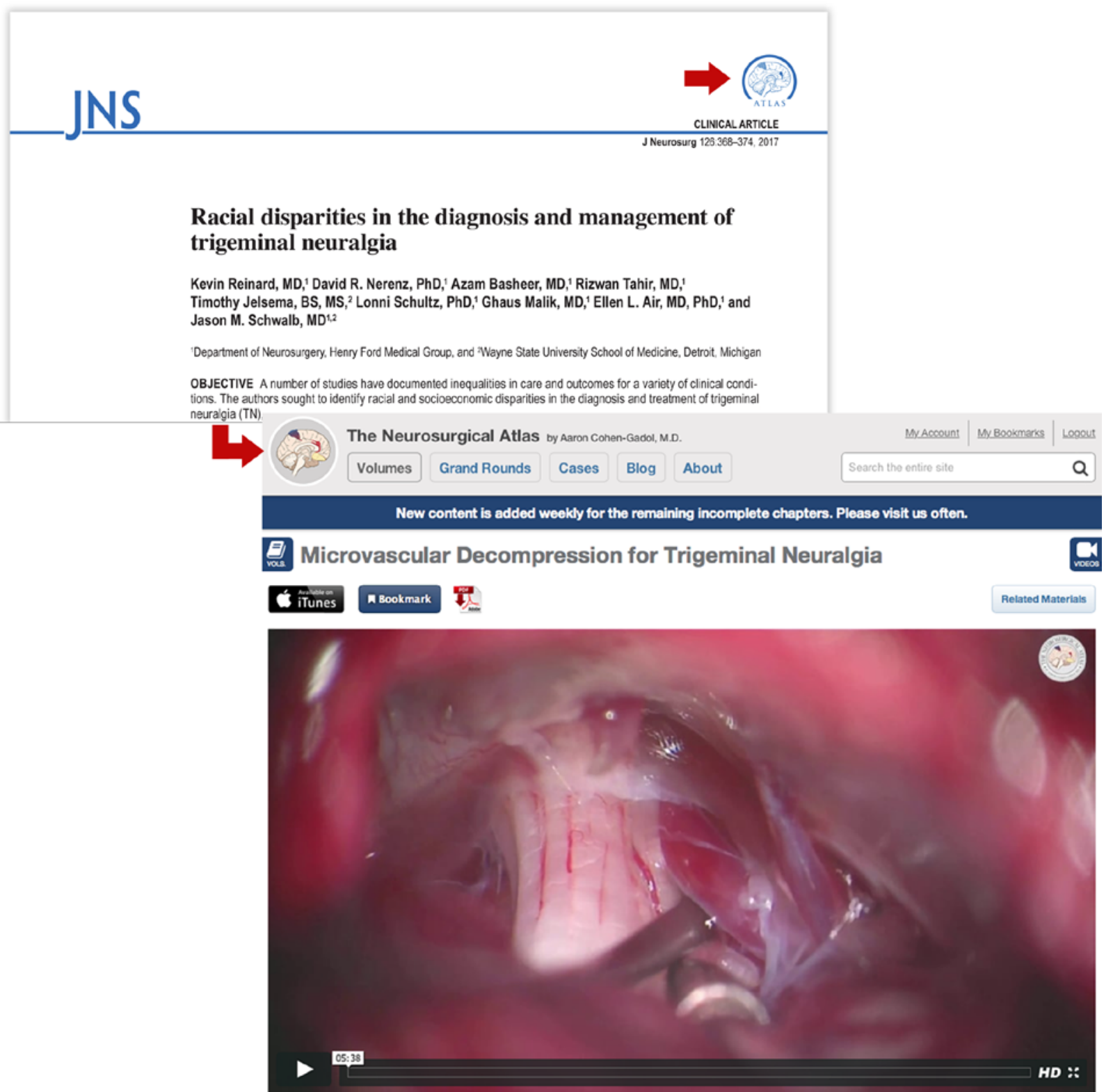

Microvascular Decompression Surgery for Trigeminal Neuralgia: Classical Intraoperative Findings

FIG. 2. Illustration of how to go to the landing page of an appropriately selected video sequence of a specific neurosurgical condition in The Neurosurgical Atlas. Clicking on the Atlas icon (arrow) in the top right corner of the PDF of select Journal of Neurosurgery articles leads to the corresponding landing page of the Atlas (right-angled arrow). Figure is available in color online only.

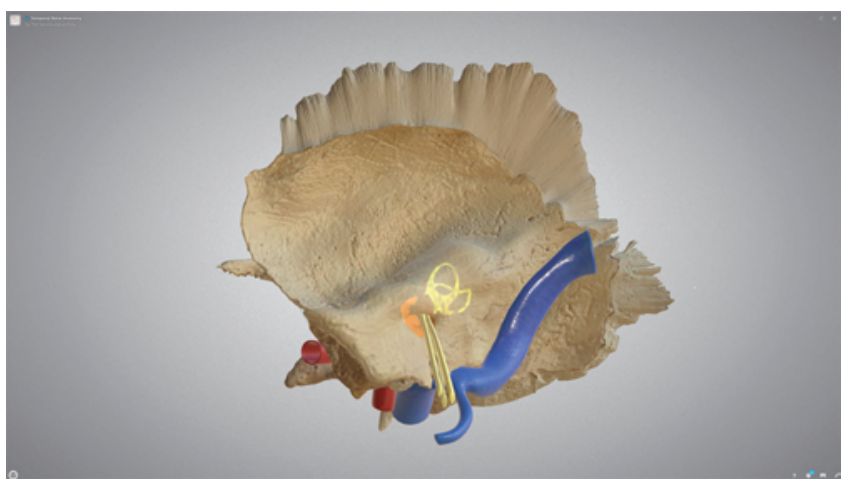

FIG. 3. An example of temporal bone anatomy and deep structures. The viewer can interact with the model in 3D space; instructions guide the reader on the use of the model: http://www.neurosurgicalatlas. com/volumes/cranial-base-surgery/skull-base-exposures/anteriorpetrosectomy. Reproduced with permission from Aaron A. CohenGadol: The Neurosurgical Atlas. Figure is available in color online only. 


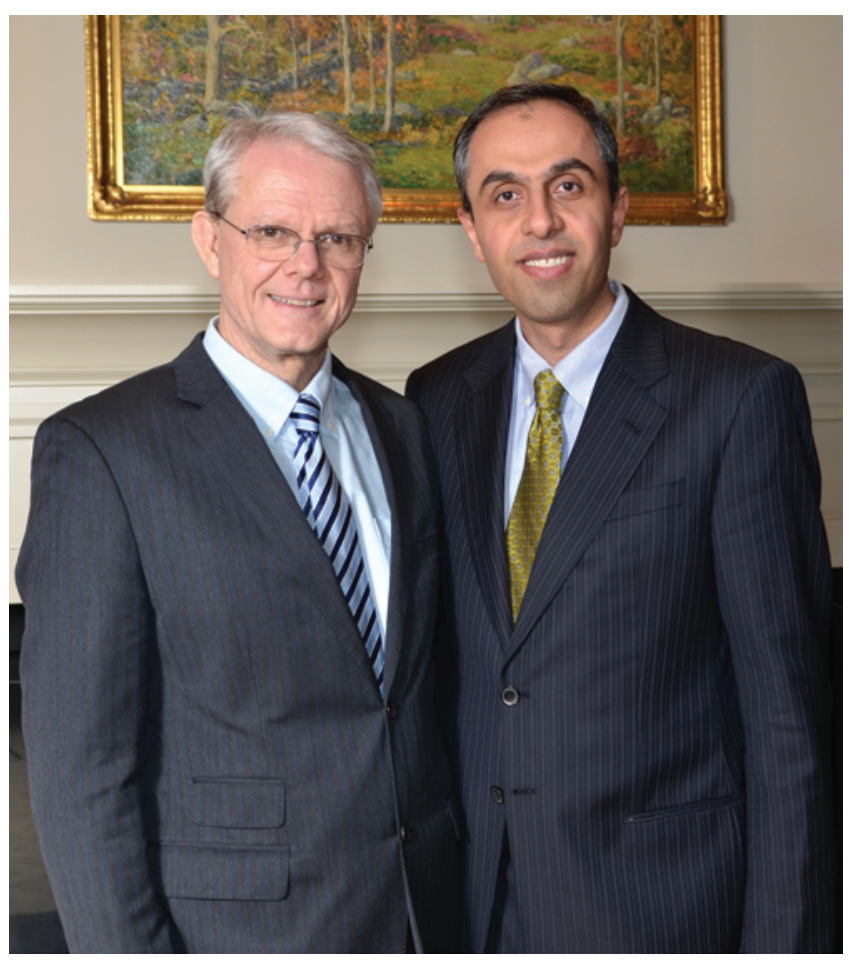

FIG. 4. Photograph of the author (left) with the creator and president of The Neurosurgical Atlas, Inc.: Aaron Cohen-Gadol, Professor of Neurosurgery, Goodman Campbell Brain and Spine, Indiana University. Courtesy of Goodman Campbell Brain and Spine, Indiana University Department of Neurosurgery. Published with permission. Figure is available in color online only.

The Neurosurgical Atlas and the Journal of Neurosurgery, we will be able to track the impressions made by readers interested in supplementing their knowledge of the neurosurgical conditions outlined in journal articles with the beautifully illustrated chapters of The Neurosurgical Atlas, replete with its video materials.

Exciting upcoming additions to The Neurosurgical Atlas include the introduction of readily rendered interac- tive 3D computer graphics engines (Web Graphics Library [WebGL]) that provide an unexplored and novel level of interactivity with brain models that depict complex anatomy in 3D space (Fig. 3). This technology is another example of the unwavering commitment and core value of The Neurosurgical Atlas as a partner of JNSPG to remain a most innovative and comprehensive platform for offering state-of-the-art content and technology for advancement of neurosurgical techniques.

I should like to take this opportunity to thank Aaron Cohen-Gadol sincerely for allowing us to link content from the Journal with the unique and powerful resource of The Neurosurgical Atlas (Fig. 4). I encourage all of you to take full advantage of improving your knowledge base in neurosurgery, of enhancing your understanding of the relevant regional neuroanatomy that is critically important in taking care of your patients in surgery, and of improving your skills by visiting relevant, and appropriately selected, video footage in advance of performing surgery in your cases. If a picture is worth a thousand words, just imagine the relative worth in words of an operative video! https://thejns.org/doi/abs/10.3171/2016.12.JNS163140

\section{References}

1. McBeth PB, Louw DF, Yang F, Sutherland GR: Quantitative measures of performance in microvascular anastomoses. Comput Aided Surg 10:173-180, 2005

2. Rapp AK, Healy MG, Charlton ME, Keith JN, Rosenbaum ME, Kapadia MA: YouTube is the most frequently used educational video source for surgical preparation. J Surg Educ 73:1072-1076, 2016

3. Rutka JT: Editorial. The Rhoton Collection and the Journal of Neurosurgery: expanding the reach of neuroanatomy in the digital print world. J Neurosurg 125:4-6, 2016

4. Sarkiss CA, Philemond S, Lee J, Slobotka S, Holloway TD, Moore MM, et al: Neurosurgical skills assessment: measuring technical proficiency in neurosurgery residents through intraoperative video evaluations. World Neurosurg 89:1-8, 2016

\section{Disclosures}

The author reports no conflict of interest. 